\title{
Insights into ventilation-gas exchange coupling in chronic thromboembolic pulmonary hypertension
}

\author{
To the Editor:
}

Exercise intolerance due to excessive ventilation and dyspnoea are fundamental clinical features of patients with pulmonary vascular diseases [1]. Among these diseases, chronic thromboembolic pulmonary hypertension (CTEPH) is associated with the largest increase in exercise ventilation [2]. Understanding the mechanism(s) underlying excess exercise ventilation in CTEPH is clinically relevant when designing evidence-based therapeutic and rehabilitative strategies to improve patients' symptoms and quality of life.

Excess exercise ventilation in CTEPH has been traditionally ascribed to increased "wasted" ventilation, i.e. hypoperfusion of well-ventilated alveoli. In fact, the physiological dead space fraction of tidal volume (VD/VT ratio) at peak exercise not only predicts CTEPH after pulmonary embolism [3] but also improves after clinical [4] and surgical [5] treatment. As the end-tidal carbon dioxide tension $\left(P \mathrm{ETCO}_{2}\right)$ diminishes when ventilation is excessive relative to perfusion [6], increased $V \mathrm{D} / V \mathrm{~T}$ has been mechanistically linked to inordinately low $\mathrm{PETCO}_{2}$ in CTEPH [7]. A $\mathrm{PETCO}_{2}$ lower than arterial (a) carbon dioxide tension $\left(\mathrm{PCO}_{2}\right)$ (i.e. a positive $P(\mathrm{a}-\mathrm{ET}) \mathrm{CO}_{2}$ gradient) [6] also suggests impaired pulmonary perfusion as a potential explanation for low exercise $\mathrm{PETCO}_{2}$ in these patients [8].

Surprisingly, however, seminal studies comparing lung absorption of multiple inert gases showed no or a limited increase in $V \mathrm{D} / V \mathrm{~T}$ despite marked pulmonary arterial obstruction [9]. This prompts an alternative (or complementary) explanation for a low exercise $\mathrm{PETCO}_{2}$ in $\mathrm{CTEPH}$ : reduced alveolar $\mathrm{PCO}_{2}$ (hyperventilation) [10]. In fact, heightened neural drive has been found in pulmonary vascular diseases secondary to increased chemosensitivity [11] and/or higher afferent stimuli from "central" baro- and mechano-receptors [12]. Thus, alveolar hyperventilation under the stress of exercise may also explain the relatively lower $\mathrm{PETCO}_{2}$ in CTEPH. A hyperbolic correlation between increasing minute ventilation $\left(V^{\prime} \mathrm{E}\right) /$ carbon dioxide production $\left(V^{\prime} \mathrm{CO}_{2}\right)$ and decreasing arterial carbon dioxide tension $\left(\mathrm{PaCO}_{2}\right)$ in $\mathrm{CTEPH}$ is also suggestive of heightened neural drive and consistent with the alveolar equation [13].

There is another intriguing feature of the $\mathrm{PETCO}_{2}$ response that brings additional uncertainty about the meaning of a low exercise $\mathrm{PETCO}_{2}$ in CTEPH. Similar to pulmonary arterial hypertension (PAH) [9], $\mathrm{PETCO}_{2}$ paradoxically increases (instead of further decreasing as in normal subjects) as soon as CTEPH patients enter the recovery phase. In this context, evaluation of $\mathrm{PaCO}_{2}$ (or arterialised capillary $\left(P_{\mathrm{cCO}}\right)$ as its surrogate) [8] and $P(\mathrm{c}-\mathrm{ET}) \mathrm{CO}_{2}$ across the exercise-to-recovery transition might shed light on the mechanisms underlying the $\mathrm{PETCO}_{2}$ behaviour during recovery in $\mathrm{CTEPH}$. Thus, we reasoned that during recovery: 1) if $\mathrm{PCCO}_{2}$ remains stable or further decreases despite higher $P \mathrm{ETCO}_{2}$, a narrower $P(\mathrm{c}-\mathrm{ET}) \mathrm{CO}_{2}$ would suggest improved $V \mathrm{D} / V \mathrm{~T}$ (scenario 1); 2) conversely, if $\mathrm{PCCO}_{2}$ and $\mathrm{PETCO}_{2}$ increase proportionally leading to stable $P(\mathrm{c}-\mathrm{ET}) \mathrm{CO}_{2}$, lower neural drive would explain higher $P \mathrm{ETCO}_{2}$ (scenario 2); 3) but if a narrower $P(\mathrm{c}-\mathrm{ET}) \mathrm{CO}_{2}$ develops as a consequence of $P_{\mathrm{CCO}_{2}}$, increasing less than $P \mathrm{ETCO}_{2}$, improved $V \mathrm{D} / V \mathrm{~T}$ plus lower neural drive would explain a higher $\mathrm{PETCO}_{2}$ (scenario 3).

We therefore measured $\mathrm{P}_{\mathrm{CCO}_{2}}$ (arterialised ear lobe blood), $P(\mathrm{c}-\mathrm{ET}) \mathrm{CO}_{2}$ and plasma lactate 1 min before peak incremental exercise, at peak and in recovery at every minute up to the fifth minute of unloaded cycling. Responses from 10 patients (age 54-78 years, five males, mean \pm SE pulmonary arterial pressure $51.5 \pm 9.7 \mathrm{mmHg}$, pulmonary wedge pressure $9.2 \pm 3.4 \mathrm{mmHg}$, stable segmental perfusion defects after 6 months of anticoagulation) were contrasted with those from eight age- and sex-matched healthy subjects. As expected, patients had a lower peak oxygen uptake, $V^{\prime} \mathrm{CO}_{2}$ and arterial oxygen saturation measured by pulse oximetry $\left(S_{\mathrm{pO}_{2}}\right)(\mathrm{p}<0.05)$. Lactate corrected for peak work rate was higher in patients 

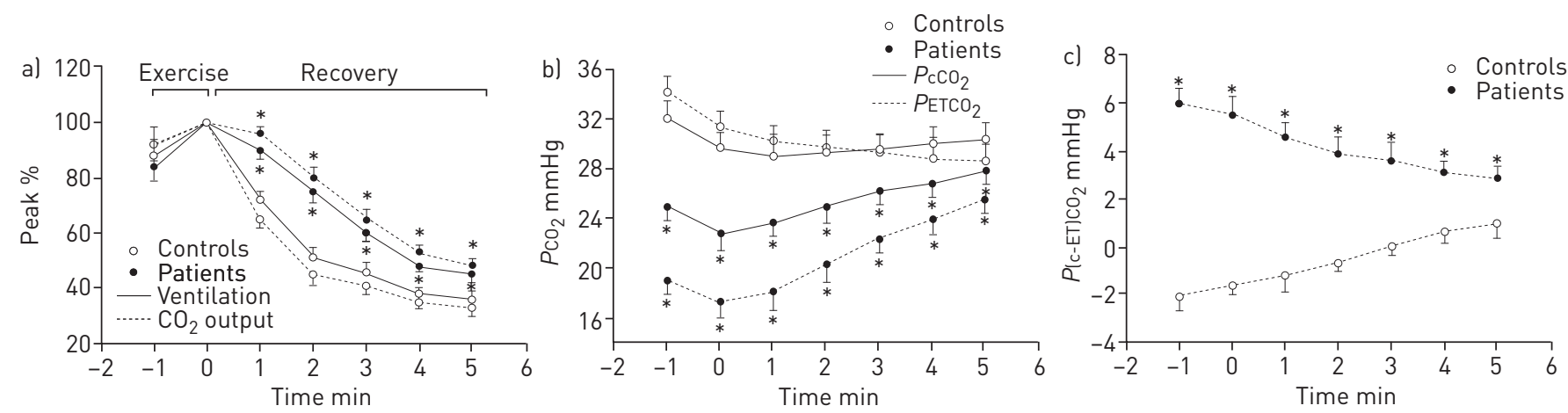

FIGURE 1 a) Ventilation, carbon dioxide $\left(\mathrm{CO}_{2}\right)$ output, b) capillary carbon dioxide tension $\left(\mathrm{P}_{\mathrm{c}} \mathrm{CO}_{2}\right)$ and capillary end-tidal carbon dioxide tension $\left(\mathrm{PETCO}_{2}\right)$, and $\left.\mathrm{c}\right)$ their differences during exercise and recovery in patients with chronic thromboembolic pulmonary hypertension and healthy controls. Data are presented as mean \pm SE. *: p<0.05 for inter-group comparisons at a given time-point.

$\left(0.14 \pm 0.05\right.$ versus $\left.0.08 \pm 0.04 \mathrm{mEq} \cdot \mathrm{L}^{-1} \cdot \mathrm{W}^{-1} ; \mathrm{p}<0.01\right)$. These findings were associated with lower peak $P_{\mathrm{ETCO}}$ and positive $P(\mathrm{c}-\mathrm{ET}) \mathrm{CO}_{2}$ (figure $1 \mathrm{~b}$ ).

In line with our previous observations, whereas recovery $\mathrm{PETCO}_{2}$ consistently increased throughout recovery in patients, it remained lower than peak exercise in controls (figure 1b). This increased $\mathrm{PETCO}_{2}$ was associated with a faster decline in $V^{\prime} \mathrm{E}$ compared with $V^{\prime} \mathrm{CO}_{2}$ in patients; conversely, $V^{\prime} \mathrm{E}$ recovered at a slower rate than $V^{\prime} \mathrm{CO}_{2}$ in controls (figure 1a). Lactate remained similarly increased in both groups; conversely, $\mathrm{SpO}_{2}$ was lower in patients up to the third minute of recovery $(91.1 \pm 3.5 \%$ versus $96.4 \pm 2.0 \%$; $\mathrm{p}<0.05)$. In controls, $\mathrm{PCCO}_{2}$ further decreased up to the second minute and remained stable thereafter, i.e. a negative $P(\mathrm{c}-\mathrm{ET}) \mathrm{CO}_{2}$ was found for most of recovery. In patients, $\mathrm{P}_{\mathrm{CCO}_{2}}$ increased throughout recovery; however, as it increased less than $P \mathrm{ETCO}_{2}, P(\mathrm{c}-\mathrm{ET}) \mathrm{CO}_{2}$ systematically decreased in $\mathrm{CTEPH}$ (figure 1c). Under the logical assumption that recovery reversed the abnormalities seen during exercise, scenario 3 seems in line with the suggestions of Delcroix et al. [10] and Naeije and van De Borne [11] that both high VD/VT and heightened neural drive are related to excess exercise ventilation in CTEPH.

As pointed out by the late eminent physiologist Brian J. Whipp, the transition between different rates of metabolic demand (e.g. exercise-recovery) provides a unique window to understand the complexities linking tissue gas exchange to pulmonary ventilation [14]. Thus, when $V^{\prime} \mathrm{CO}_{2}$ slowly decreased after exercise in our patients, $V^{\prime} \mathrm{E}$ did not lag behind as in normal subjects. Conversely, $V^{\prime} \mathrm{E}$ decreased consistently faster than $V^{\prime} \mathrm{CO}_{2}$ in patients (figure 1a). The sudden decrease in $V^{\prime} \mathrm{E}$ and resulting elevation in $P_{\mathrm{CCO}_{2}}$ (figure 1b) suggest an abrupt reduction in neural drive in these patients. Sluggish muscle gas exchange kinetics due to a slower rate of phosphocreatine replenishment and/or slower cardiocirculatory dynamics during recovery may have contributed to a more protracted $V^{\prime} \mathrm{CO}_{2}$ in patients [14]. It is also conceivable that carbon dioxide released during exercise has been slowly washed-out from carbon dioxide reservoirs, which are likely to be larger in chronically hypocapnic patients [15]. In fact, resting $\mathrm{PaCO}_{2}$ and exercise-induced decrements in $P_{c} \mathrm{CO}_{2}$ were closely related to $V^{\prime} \mathrm{CO}_{2}$ kinetics in patients $(\mathrm{r}=0.85$ and $\mathrm{r}=0.88$, respectively; $\mathrm{p}<0.001)$. Although additional studies are needed to clarify the underlying mechanism(s), it is clear that $V^{\prime} \mathrm{E}$ did not "wait" for $V^{\prime} \mathrm{CO}_{2}$, which resulted in post-exercise decreases in the $V^{\prime} \mathrm{E} / V^{\prime} \mathrm{CO}_{2}$ ratio, thereby contributing to increase $\mathrm{PETCO}_{2}$ in CTEPH.

Another key finding relates to a $P(\mathrm{c}-\mathrm{ET}) \mathrm{CO}_{2}$ decrease after exercise in patients, which seems consistent with post-exercise improvement in $V \mathrm{D}$, likely to be secondary to enhanced pulmonary perfusion and ventilation/perfusion matching [6, 7]. ZHAI et al. [13] found that while $V^{\prime} \mathrm{E} / V^{\prime} \mathrm{CO}_{2}$ (assumed as an index of $V \mathrm{D} / V \mathrm{~T}$ behaviour) for a given $\mathrm{PaCO}_{2}$ was increased in CTEPH compared with $\mathrm{PAH}$, the difference disappeared when $V^{\prime} \mathrm{E} / V^{\prime} \mathrm{CO}_{2}$ was expressed as a function of $P \mathrm{ETCO}_{2}$. This suggests a greater contribution of increased $V$ D to the excessive exercise ventilation (and low $\mathrm{PETCO}_{2}$ ) in CTEPH compared with PAH during exercise.

In conclusion, increased "wasted" ventilation (high $V \mathrm{D} / V \mathrm{~T}$ ) is not the only explanation for excess exercise ventilation in CTEPH: heightened neural drive also contributes to these abnormalities. Interventions able to decrease both $V \mathrm{D} / V_{\mathrm{T}}$ and neural drive might prove particularly valuable in this patient population. 
J. Alberto Neder ${ }^{1,2}$, Roberta P. Ramos ${ }^{1,3}$, Jaquelina S. Ota-Arakaki ${ }^{1,3}$, Eloara M.V. Ferreira ${ }^{1,3}$, Daniel M. Hirai ${ }^{1,2}$, Priscila A. Sperandio ${ }^{1}$, Maria Clara N. Alencar ${ }^{1}$, Flavio F. Arbex ${ }^{1}$, Danilo C. Berton ${ }^{4}$, Christine D'Arsigny ${ }^{2}$ and Denis E. O'Donnell ${ }^{2}$

${ }^{1}$ Pulmonary Function and Clinical Exercise Physiology Unit, Respiratory Division, Dept of Medicine, School of Medicine, Federal University of São Paulo, São Paulo, Brazil. ${ }^{2}$ Laboratory of Clinical Exercise Physiology and Respiratory Investigation Unit, Division of Respiratory and Critical Care Medicine, Dept of Medicine, Queen's University, Kingston, ON, Canada. ${ }^{3}$ Pulmonary Vascular Group, Respiratory Division, Dept of Medicine, School of Medicine, Federal University of São Paulo, São Paulo, Brazil. ${ }^{4}$ Respiratory Division, Dept of Medicine, Federal University of Rio Grande do Sul, Porto Alegre, Brazil.

Correspondence: J. Alberto Neder, Division of Respiratory and Critical Care Medicine, Queen's University and Kingston General Hospital, Richardson House, 102 Stuart Street, Kingston, ON K7L 2V6, Canada. E-mail: nederalb@gmail.com

Received: Nov 212015 | Accepted after revision: Feb 282016 | First published online: April 132016

Conflict of interest: None declared.

\section{References}

Mélot C, Naeije R. Pulmonary vascular diseases. Compr Physiol 2011; 1: 593-619.

2 Neder JA, Ramos RP, Ota-Arakaki JS, et al. Exercise intolerance in pulmonary arterial hypertension. The role of cardiopulmonary exercise testing. Ann Am Thorac Soc 2015; 12: 604-612.

3 McCabe C, Deboeck G, Harvey I, et al. Inefficient exercise gas exchange identifies pulmonary hypertension in chronic thromboembolic obstruction following pulmonary embolism. Thromb Res 2013; 132: 659-665.

4 Claessen G, La Gerche A, Wielandts J-Y, et al. Exercise pathophysiology and sildenafil effects in chronic thromboembolic pulmonary hypertension. Heart Br Card Soc 2015; 101: 637-644.

5 van der Plas MN, Reesink HJ, Roos CM, et al. Pulmonary endarterectomy improves dyspnea by the relief of dead space ventilation. Ann Thorac Surg 2010; 89: 347-352.

6 Hansen JE, Ulubay G, Chow BF, et al. Mixed-expired and end-tidal $\mathrm{CO}_{2}$ distinguish between ventilation and perfusion defects during exercise testing in patients with lung and heart diseases. Chest 2007; 132: 977-983.

7 Yasunobu Y, Oudiz RJ, Sun X-G, et al. End-tidal $\mathrm{PCO}_{2}$ abnormality and exercise limitation in patients with primary pulmonary hypertension. Chest 2005; 127: 1637-1646.

8 Scheidl SJ, Englisch C, Kovacs G, et al. Diagnosis of CTEPH versus IPAH using capillary to end-tidal carbon dioxide gradients. Eur Respir J 2012; 39: 119-124.

9 Dantzker DR, Bower JS. Mechanisms of gas exchange abnormality in patients with chronic obliterative pulmonary vascular disease. J Clin Invest 1979; 64: 1050-1055.

10 Delcroix M, Vonk Noordegraaf A, Fadel E, et al. Vascular and right ventricular remodelling in chronic thromboembolic pulmonary hypertension. Eur Respir J 2013; 41: 224-232.

11 Naeije R, van de Borne P. Clinical relevance of autonomic nervous system disturbances in pulmonary arterial hypertension. Eur Respir J 2009; 34: 792-794.

12 Theodore J, Robin ED, Morris AJ, et al. Augmented ventilatory response to exercise in pulmonary hypertension. Chest 1986; 89: 39-44.

13 Zhai Z, Murphy K, Tighe H, et al. Differences in ventilatory inefficiency between pulmonary arterial hypertension and chronic thromboembolic pulmonary hypertension. Chest 2011; 140: 1284-1291.

14 Whipp BJ. The bioenergetic and gas exchange basis of exercise testing. Clin Chest Med 1994; 15: 173-192.

15 Ward SA, Whipp BJ, Koyal S, et al. Influence of body $\mathrm{CO}_{2}$ stores on ventilatory dynamics during exercise. J Appl Physiol 1983; 55: 742-749.

\section{Diagnostic concordance of different criteria for exercise pulmonary hypertension in subjects with normal resting pulmonary artery pressure}

To the Editor:

Pulmonary hypertension is defined by a resting mean pulmonary artery pressure (mPAP) $\geqslant 25 \mathrm{mmHg}$ [1]. Despite a better understanding of the biology of pulmonary hypertension and new therapeutic advances, pulmonary hypertension remains diagnosed late in its natural history and is largely a non-curable condition [2]. Recently, there has been renewed interest in stress-testing of the pulmonary circulation since the early stages of pulmonary vascular disease (PVD) or left heart disease (LHD) can be associated with normal resting mPAP but an abnormal haemodynamic response that is unmasked by exercise [3-5]. 